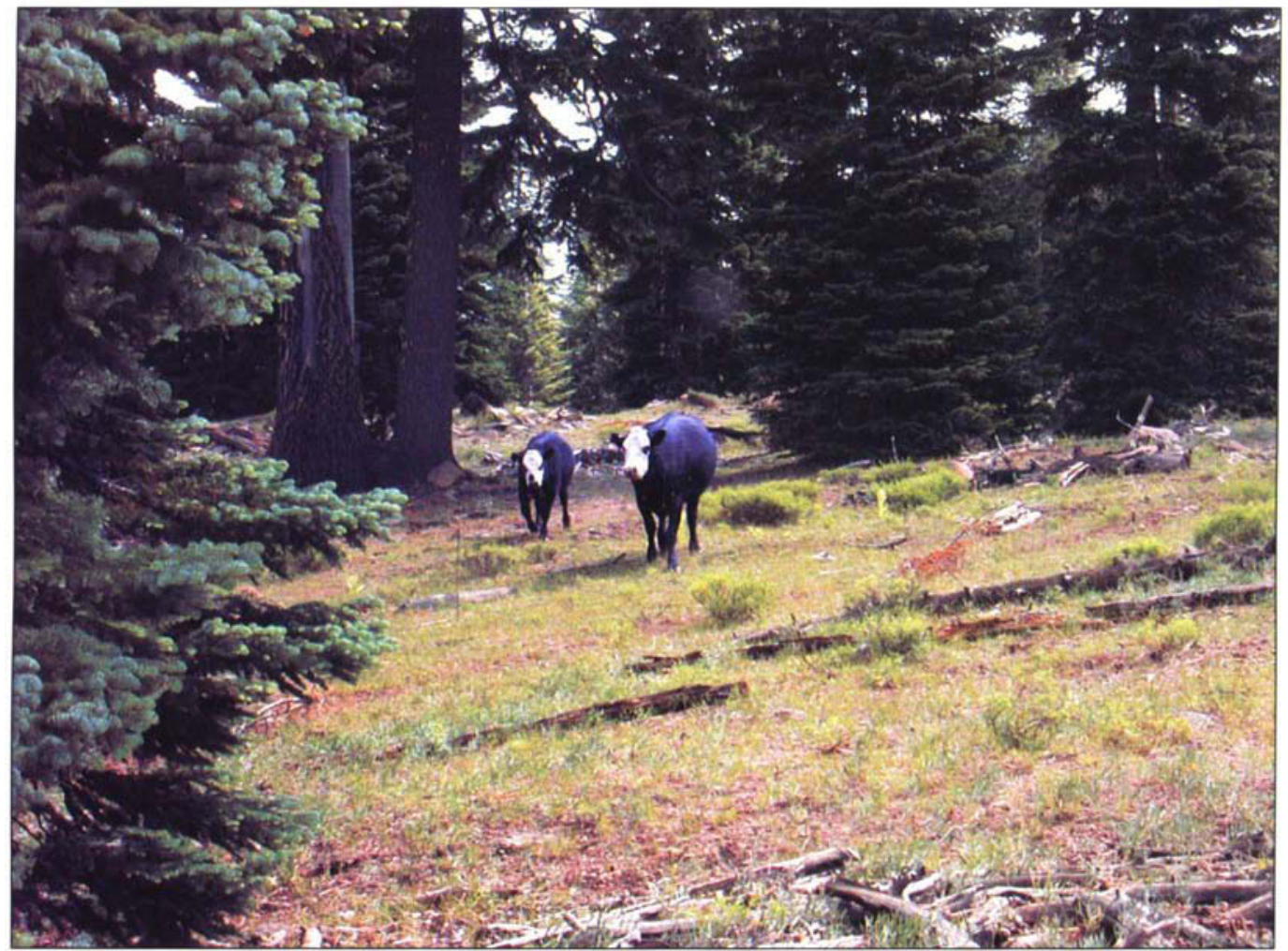

The prevalence of major internal parasites in beef cattle varies widely in California, but overall rates are high.

\title{
Internal parasites prevalent in California's beef cattle
}

\author{
Daniel J. Drake a Edward R. Atwill $\square$ Ralph Phillips $\square$ Eileen Johnson
}

\begin{abstract}
Sixty percent of cattle not dewormed within 4 months of sampling were shedding parasite eggs or larva. The prevalence of shedding varied greatly for different types of internal parasites. Prevalence of shedding for major Strongylate nematodes was 54\%; thread-necked intestinal nematodes, $6 \%$; lungworms, $0.8 \%$; coccidia, $18.1 \%$; and tapeworms, 2.1\%. Anthelmintic (deworming) treatments lowered prevalence compared to untreated cattle, but the major Strongylate nematodes and coccidia were still sufficiently prevalent that the resulting pasture contamination would restrict the potential success of control programs.
\end{abstract}

Qeef cattle have a long history of 3 suffering from internal parasites that result in reduced weight gain and poor feed conversion. Producers, recognizing that reduced performance can result, have adopted parasite control programs. The principal control activities are grazing management to avoid infective stages of parasites and the strategic use of anthelmintics (deworming medications). We surveyed producers and sampled cattle to describe the prevalence of five types of internal parasites in California's beef cattle and to identify management factors important to parasite control.

Thirty-five herds representing 16 counties across a wide range of climatic and geographic areas of California were selected for sampling in 1995 (fig. 1). The sample herds for five types of internal parasites were initially selected to participate in a companion survey focused on the protozoa Cryptosporidium spp. Herd selection for the Cryptosporidium study was random. In addition, at the time of sampling and survey completion, cooperating producers and survey administrators were not aware of the internal parasite study.

UC Cooperative Extension livestock farm advisors obtained samples of manure from 1,323 individual, randomly selected cattle between February and August 1995 (table 1). The number of cattle sampled at each location ranged from 18 to 71 head (mean 38 head). Samples were taken by rectal grab or from fresh manure pats when individual animal identification was possible. Samples were refrigerated and 
processed in an appropriate manner for each of five major parasite types:

Major Strongylate nematodes (previously strongylid)

- Ost tagia sp., Haemonchus sp., Trichostrongylus spp., Cooperia spp., Oesophagostomum sp., Bunostomum sp. and Chabertia sp. These include hair worms, hookworms and largemouthed bowel worms.

Minor Strongylate nematodes

- Thrad-necked intestinal worms (Nematodirus spp.).

- Lungworms (Dictyocaulus viviparus).

Other parasites

- Coctidia (Eimeria spp.).

- Tapworms (Moniezia spp.).

Major Strongylate classification did not differentiate among Ostertagia sp., Haemonchus sp., Trichostrongylus spp., Cooperia spp., Oesophagostomum sp. and Chabertia sp., and is used here to represent these major Strongylate species. The minor Strongylates (threadnecked intestinal worms and lungworms) were differentiated and are discussed separately. Individual cattle were classified as positive by evidence of parasite eggs/larvae using fecal flotation and microscopic examination. The survey is conservative, limited to cattle that were shedding eggs/larvae at the time of the survey and to only one sample. A survey form was completed at the time of sampling for each herd (available from the authors).

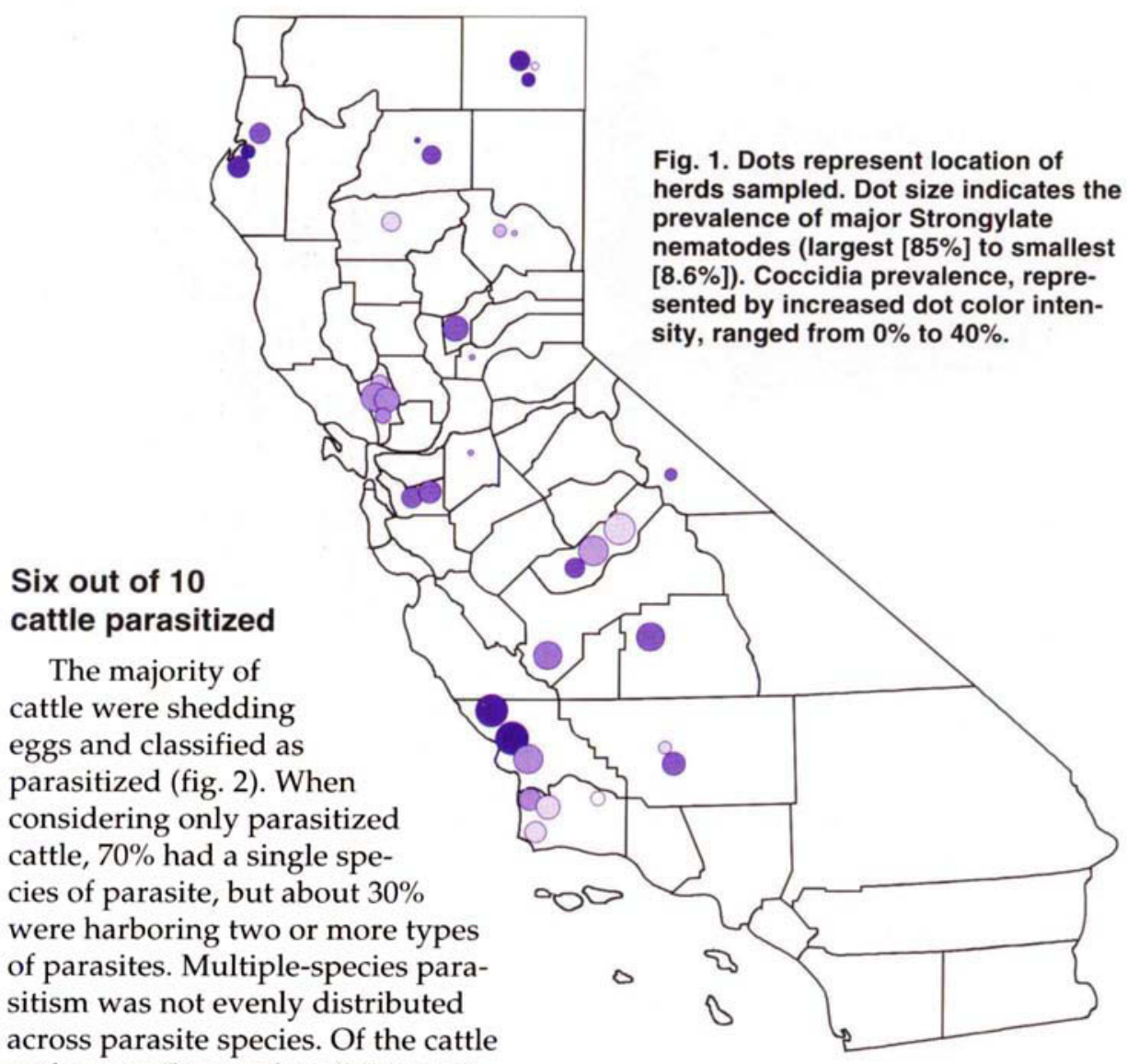

with major Strongylate (686 head),

$33.4 \%$ had two or more types of parasites. This contrasts with those parasit- an individual with major Strongylate ized with coccidia ( 248 head), thread- will have another parasite species. necked intestinal worms (76 head), tapeworms (30 head) and lungworms (11 head), which had $68 \%, 92 \%, 86 \%$ and $81 \%$, respectively, with multipleparasite species; a diagnosis of any of these should alert producers that other parasites are likely to be present. Chances are only one out of three that
TABLE 1. Percent of cattle shedding eggs for five internal parasites, by California county

\begin{tabular}{|c|c|c|c|c|c|c|c|}
\hline \multirow[b]{2}{*}{ County } & \multirow[b]{2}{*}{$\begin{array}{l}\text { Number } \\
\text { of herds }\end{array}$} & \multirow[b]{2}{*}{$\begin{array}{l}\text { Number } \\
\text { of cattle }\end{array}$} & \multicolumn{5}{|c|}{ Percentages positive for egg shedding } \\
\hline & & & $\begin{array}{c}\text { Major } \\
\text { Strongylate }\end{array}$ & Coccidia & $\begin{array}{l}\text { Thread-necked } \\
\text { intestinal worm }\end{array}$ & Tapeworm & Lungworm \\
\hline Alameda & 2 & 77 & 66.2 & 22.1 & 10.4 & 7.8 & 0.0 \\
\hline Fresno & 1 & 37 & 73.0 & 18.9 & 13.5 & 2.7 & 0.0 \\
\hline Humboldt & 3 & 115 & 49.6 & 30.4 & 1.7 & 3.5 & 0.9 \\
\hline Inyo & 1 & 42 & 31.0 & 21.4 & 0.0 & 0.0 & 0.0 \\
\hline Kern & 2 & 79 & 46.8 & 13.9 & 0.0 & 0.0 & 0.0 \\
\hline Madera & 3 & 118 & 68.6 & 14.4 & 5.9 & 16.9 & 0.0 \\
\hline Modoc & 3 & 126 & 36.5 & 27.0 & 2.4 & 0.8 & $0.0^{-}$ \\
\hline Napa & 4 & 153 & 56.2 & 13.7 & 2.6 & 1.3 & 0.0 \\
\hline Placer & 1 & 42 & 14.3 & 14.3 & 9.5 & 0.0 & 0.0 \\
\hline Plumas & 2 & 68 & 20.6 & 8.8 & 0.0 & 1.5 & 0.0 \\
\hline San Joaquin & 1 & 24 & 12.5 & 12.5 & 0.0 & 0.0 & 0.0 \\
\hline San Luis Obispo & 3 & 93 & 81.7 & 32.2 & 11.8 & 5.4 & 0.0 \\
\hline Santa Barbara & 4 & 162 & 53.1 & 7.4 & 8.6 & 2.5 & 0.6 \\
\hline Shasta & 2 & 51 & 35.3 & 29.4 & 0.0 & 0.0 & 0.0 \\
\hline Tehema & 1 & 39 & 48.7 & 7.7 & 12.8 & 2.6 & 12.8 \\
\hline Tulare & 1 & 26 & 73.1 & 23.1 & 3.8 & 11.5 & 0.0 \\
\hline Yuba/Sutter & 1 & 71 & 66.2 & 22.5 & 16.9 & 0.0 & 5.6 \\
\hline Total & 35 & 1,323 & 51.9 & 18.7 & 5.7 & 2.3 & 0.8 \\
\hline
\end{tabular}

During the 4-month period before sampling, anthelmentics had been administered to $8.5 \%$ of the cattle. Of the cattle receiving an anthelmintic product, $38 \%$ were shedding parasite eggs, compared to $60 \%$ of cattle that had not been treated (table 2). Products were not equally effective

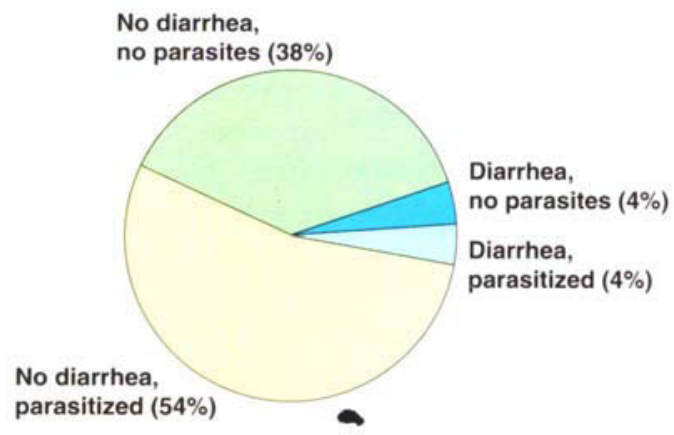

Fig. 2. Diarrhea was observed in only $8 \%$ of cattle sampled; parasites were found at about the same rate whether cattle had diarrhea or not. Treating only diarrheic cattle would result in treatment of some nonparasitized cattle, while many more parasitized cattle would be missed. 
TABLE 2. Percent cattle shedding parasite eggs

\begin{tabular}{lccc}
\hline \hline & Dewormed* & $\begin{array}{c}\text { Not } \\
\text { dewormed }\end{array}$ & $\begin{array}{c}\mathbf{P} \\
\text { value }\end{array}$ \\
\hline $\begin{array}{l}\text { Any parasite } \\
\text { Strongylate }\end{array}$ & 38.2 & 60.1 & .0001 \\
$\begin{array}{l}\text { Coccidia } \\
\text { Thread-necked }\end{array}$ & 28.2 & 54.0 & .00001 \\
$\quad$ intestinal & 1.8 & 18.1 & .46 \\
$\begin{array}{l}\text { Tapeworm } \\
\text { Lungworm }\end{array}$ & 2.7 & 6.0 & .14 \\
\hline
\end{tabular}

"Receiving an anthelmintic product (albendazole, fenbendazole or ivermectin) within 4 months of sampling

†Not receiving medication within 4 months.

against the five parasites. Although treatment with a wormer did significantly lower the prevalence of cattle shedding eggs, there were still a large number of cattle potentially infecting the environment.

The low number of cattle $(8.5 \%)$ receiving an anthelmintic is surprising. One explanation is that sampling was conducted from February through August, with many of the cattle tested during April and May. Anthelmintic recommendations are frequently for fall administration to control hair worms (Ostertagia ostertagia), which are the most common pathogenic parasite of cattle. By conducting our study from late winter through summer, we may have biased downward our prevalence estimate of anthelmintic usage among cow-calf operators in California.

Diarrhea is not a diagnostic tool for parasitism, although it is sometimes a sign of parasitism when the level of infection is high. Nevertheless, producers frequently consider diarrhea to be a symptom of parasitism, regardless of

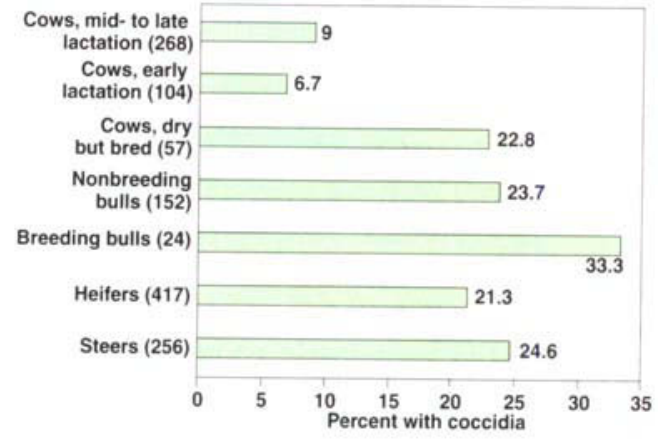

Fig. 3. Percent (and number sampled) of cattle shedding coccidia oocysts, by class. Early lactation cows (just after calving but not yet bred) and mid- to late lactation (with suckling calves and bred) had lower incidence of coccidia. the magnitude of infection. Only 56 head $(8 \%$ of the total) had a known history of diarrhea (fig. 2), yet nearly $60 \%$ of the cattle sampled were parasitized. Diarrheic calves were no more likely to be parasitized ( $48.2 \%)$ than those without diarrhea $(54 \%)$.

\section{Parasite trends}

Major Strongylate. Strongylate were the most common parasite; $51.9 \%$ of the cattle sampled were positive, and it was found in all counties sampled (table 1). Prevalence varied from $8.6 \%$ to $85.1 \%$ of the herd parasitized (table 1). Strongylate parasitism declined slightly with animal age; calves ( 1 to 11 months old) had an incidence of $55.9 \%$, compared to $52.0 \%$ in yearlings (12 to 23 months old) and $43.7 \%$ in adults (older than 23 months). Strongylate incidence in steers $(64 \%)$ and heifers $(52 \%)$ was higher than in cows (41\%). However, incidence in bulls during the breeding season $(71 \%)$ and in nonactive bulls (54\%) was also higher than in cows.

Cattle that had received an anthelmintic (fenbendazole, albendazole or ivermectin) within 4 months of sampling (110 head) had significantly lower prevalence of Strongylate (28.2\%) compared to cattle $(1,179$ head) that had not received any anthelmintic (54\%) within the previous 4 months (table 2). Anthelmintic products reduce prevalence, but a large number of cattle remain infected or become reinfected quickly after the effect of the anthelmintic is gone. These cattle could reinfest the environment.

The prevalence of Strongylate was significantly different among those receiving different types of anthelmintic. The prevalence of Strongylate after using fenbendazole-type products $(19 \%)$ as well as ivermectin-type $(6.1 \%)$ was lower $(P=0.07)$ than in nontreated or albendazole-type treated cattle. Sixty percent (24 out of 40 ) of those receiving albendazole within 4 months before sampling were parasitized by Strongylate, which is about the same as those not treated $(54 \%)$. Albendazoletype products are marketed in the United States for fluke infections, but in research trials these products are reportedly very effective for Strongylate.
Results for albendazole in this survey may be influenced by timing of treatment.

Coccidia. Coccidiosis was observed in every county that was sampled (table 1). The percent of all cattle with coccidia was $18.7 \%$ (table 1). Incidence varied from $0 \%$ to $40.4 \%$ among herds. Calves $(22.6 \%)$ and yearlings $(32.0 \%)$ had a much higher level of coccidiosis than adults $(9.1 \%)$.

Prevalence of coccidiosis in adult cows presented an unexpected pattern. Nonlactating cows that were bred that is, cows just prior to calving and bred heifers - had an incidence of coccidiosis of $22.8 \%$, which is similar to other classes of cattle (fig. 3). However, cows in mid- to late lactation that were bred $(9.0 \%)$ and cows in early lactation but not yet bred $(6.7 \%)$ had a lower prevalence of coccidiosis. This data contradicts the axiom that stress such as calving is often associated with shedding of parasites.

The data also substantiate that diarrhea is not a useful indicator of coccidiosis. Of 149 calves with coccidiosis and a known history of diarrhea, only 13 calves $(8.7 \%)$ showed diarrhea at the time of sampling. Less than onequarter $(23.2 \%)$ of those cattle with diarrhea were parasitized with coccidia.

Prevalence of coccidia following albendazole-type $(28.2 \%)$ and fenbendazole-type $(28.6 \%)$ products were similar to no treatment $(18.5 \%)$. Prevalence of coccidiosis $(8.2 \%)$ after using ivermectin-type products was lower $(P=.07)$ than with no anthelmintic $(18.5 \%)$. None of the anthelmintic products are reported to have direct effects on coccidia. Observed reductions with ivermectin-type products apparently are indirect effects.

Thread-necked intestinal worms. Only $5.7 \%$ of 1,323 cattle sampled were shedding thread-necked intestinal worm eggs. In Inyo, Kern, Madera, Plumas, San Joaquin and Shasta counties, representing 299 cattle, threadnecked intestinal worm infections were not detected. Herd prevalence ranged from $0 \%$ to $28.6 \%$. Sixteen of the 35 herds sampled, representing 583 cattle, did not have any cattle shedding thread-necked intestinal worm eggs. 
Prevalence in calves $(8.3 \%)$ and yearlings $(6.0 \%)$ was again higher than in adults $(0.5 \%)$. Breeding bulls were again significantly higher than other adults, with a prevalence of $25.0 \%$ for thread-necked intestinal worms, compared to nonbreeding bulls with $6.6 \%$ and adult cows with $0.7 \%$.

Anthelmintic (albendazole, fenbendazole or ivermectin) treatment (110 head) reduced the prevalence $(1.8 \%)$ compared to $6.0 \%$ in untreated cattle $(1,179$ head).

Tapeworms. Overall only $2.3 \%$ of all cattle showed evidence of tapeworm egg shedding (table 2). Within herds, the highest prevalence was $14.6 \%$ ( 6 out of 41 head), followed by $11.5 \%$ ( 3 out of 26 head). Most herds had no individuals shedding tapeworm eggs, or only 1 to 2 head.

The sample size of parasitized cattle was small, but yearling cattle had a significantly higher incidence $(8.0 \%)$ of tapeworms than calves $(2.1 \%)$ or adults $(1.9 \%)$. Incidence of tapeworms was similar for steers, heifers, bulls and cows.

Anthelmintic (albendazole, fenbendazole or ivermectin) treatment (110 head) did not reduce the prevalence $(5.0 \%, 4.8 \%$ and $0 \%$, respectively), compared to $2.1 \%$ in untreated cattle $(1,179$ head). This is understandable, because fenbendazole and ivermectin have no effect against tapeworms at the recommended dose.

Lungworms. Lungworms were extremely rare, with an overall incidence of $0.8 \%$ (table 2). They were found only in Humboldt (1 out of 33 head), Santa Barbara (1 out of 42 head), Tehama (5 out of 39 head) and Yuba (4 out of 71 head) counties. As with tapeworms, yearlings had a significantly higher incidence $(4.0 \%)$ than calves $(0.5 \%)$ or adults $(1.2 \%)$. The data show that among adults, cows just before calving and bred heifers had a significantly higher incidence than other cattle, which is somewhat similar to the pattern for coccidiosis.

Cattle ( 110 head) treated with anthelmintic (albendazole, fenbendazole or ivermectin) had no lungworms, compared to $0.8 \%$ of untreated cattle (1,179 head).

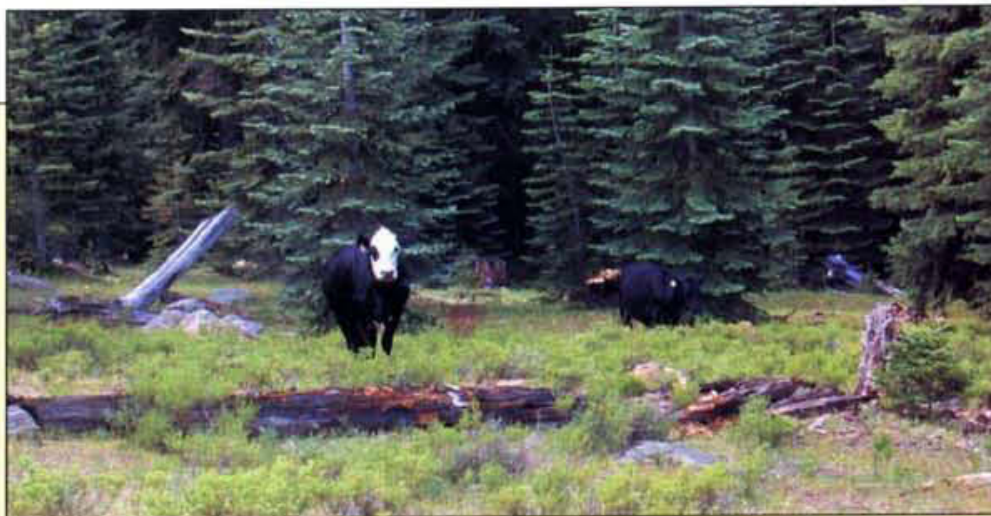

\section{It's a parasite's life}

$\mathrm{T}$ he life cycles of internal parasites are unique to each type, which can influence their geographic distribution. Understanding the life cycle of parasites, such as developmental requirements and length of life cycle, is helpful to management.

Major Strongylates (hair worms, hookworms and large-mouthed bowel worms). These worms are found in the intestinal tract. Some are very small and can be overlooked on postmortem examination. The life cycle can be completed in as little as 18 to 21 days. These worms have four larval stages. Their eggs are laid by the adult worm and passed out in the feces. The eggs hatch and go through the first two larval stages in the feces. The third larval stage (the infective stage) exits the feces and is ingested by cattle during grazing. Larvae then enter the lining of the abomasum or intestine and develop into the next stage. The fourth stage can remain in the lining for some time, or it can emerge quickly in the abomasum or intestine and develop into an adult.

Thread-necked intestinal worms (Nematodirus spp.). This worm has a life cycle similar to that just described. The main difference is that the first three larval stages develop within the eggshell. External conditions stimulate the third stage to leave the shell. At this stage, the larvae can infect cattle when ingested.

Lungworms (Dictyocaulus spp.). Adults are located in the air passages of cattle, from the respiratory bronchioles to the trachea. The life cycle is direct. These worms go through four larval stages. Adults lay eggs in the air passage, where they are coughed up and swallowed. Eggs develop into the first larval stage and hatch while passing through the alimentary tract out in the feces. The larvae develop into the infective third stage in the environment outside the animal. After the third stage is ingested, it penetrates the lining of the small intestine, where it enters the lymphatic system and migrates to the lung area and develops into the fourth stage in lymph nodes. It then emerges as an adult and moves to the lungs. The life cycle can be completed in as little as 21 or 22 days.

Coccidia (Eimeria spp.). The 21to-28-day life cycle of the coccidia protozoan begins when the mature (sporulated) oocyst is ingested by a grazing cow or from licking an infected surface, another animal or its own hide. The oocyst ruptures inside the small intestine, releasing sporozites. The cycle continues through several asexual development cycles inside the intestinal wall, where the organism infects the cells and reproduces and destroys the cells in the process, concluding when immature (nonsporulated) oocysts are excreted in feces. Outside, the oocysts sporulate in moist, oxygenated environments between $53^{\circ} \mathrm{F}$ and $90^{\circ} \mathrm{F}$, and begin the cycle again.

Tapeworms (Moniezia spp.). Eggs passed in the feces are ingested by free-living mites that live in the soil and grass. After a period of 6 to 16 weeks, infective stages (cysticercoids) are present in the mites. Infection occurs by ingestion of the mites. The time from ingestion of larvae until eggs pass into the feces, the prepatent period, is approximately 5 weeks.

-D. Drake et al. 


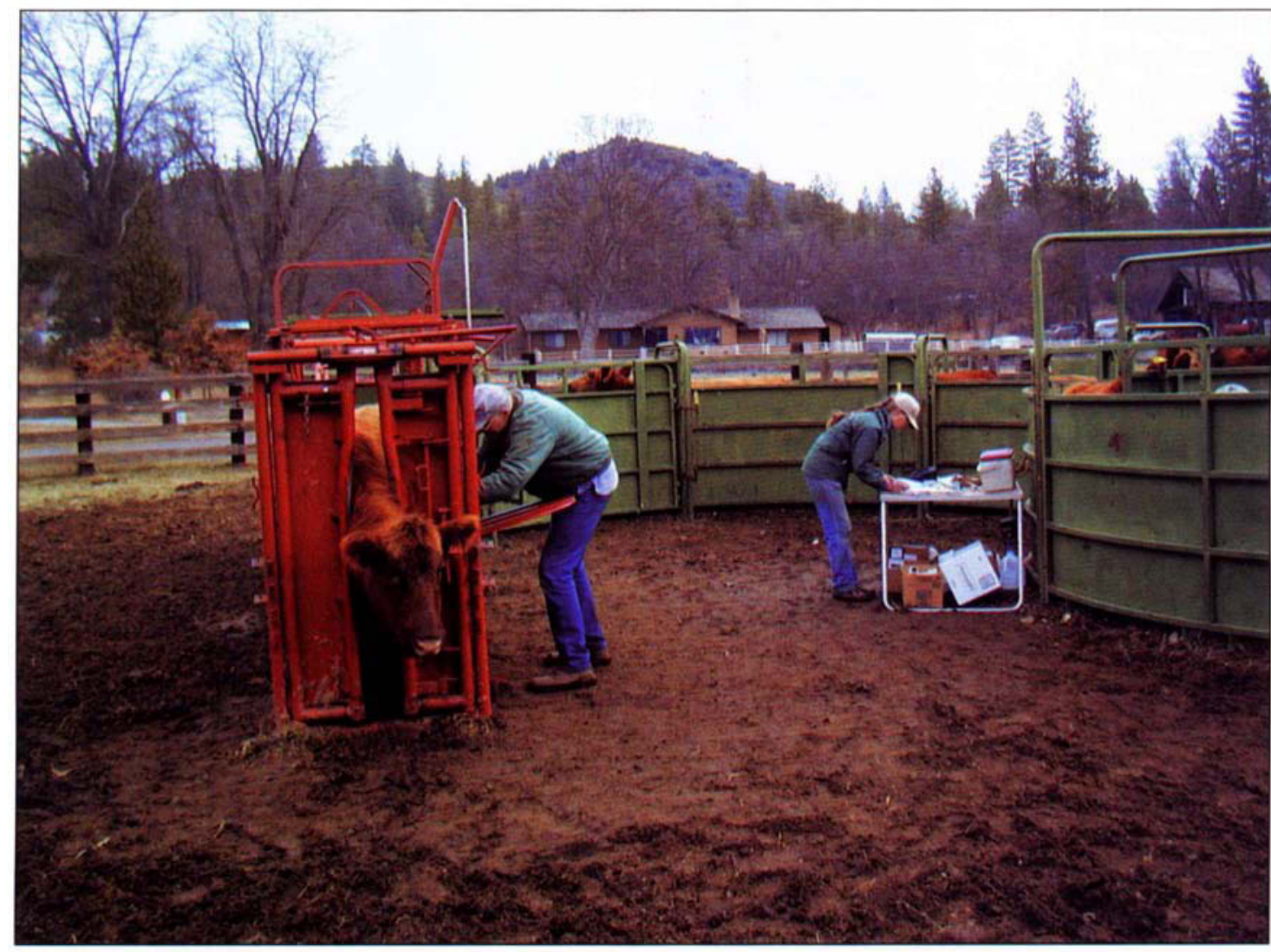

A majority of California's beef cattle not recently dewormed are parasitized. Anthelmintic treatments (deworming) lower the prevalence of internal parasites, compared to untreated cattle. At Quartz Valley Red Angus Ranch in Siskiyou County, John and Jennifer Menke tend their herd.

\section{Majority of cattle are shedding}

According to our research, a majority of California cattle are shedding parasite eggs/oocysts during the spring. These are principally major Strongylate nematodes, followed by coccidia. The minor Strongylate nematodes, thread-necked intestinal worms and lungworms, were found to a lesser degree. Anthelmintic products were effective in reducing the prevalence of egg shedding, but sufficient numbers of egg-shedding cattle remained or became reinfected, leading to the potential for contamination of the environment. Treatment of only diarrheic cattle for parasites could result in treatment of nonparasitized cattle, while large numbers of parasitized cattle without diarrhea would go untreated.

Cattle frequently have mixed parasite infections. Depending on the specific parasites, anthelmintic products may or may not be effective against multispecies parasitism. This data indicates that the current level of anthel- mintic use reduces the prevalence of parasitism, but post-treatment prevalence levels are likely to result in environmental reinfestation and result in continuing problems. Additional work is needed to develop better control programs and a better understanding of the costs and benefits of control.

D.J. Drake is UC Cooperative Extension Advisor, Siskiyou County; E.R. Atwill is Veterinary Epidemiologist, School of Veterinary Medicine, and Cooperative Extension Specialist, Veterinary Medicine Teaching and Research Center, Tulare; $R$. Phillips is UCCE Advisor, Kern County; and E. Johnson is Veterinary Parasitologist, Veterinary Medical Teaching Hospital, UC Davis. The authors are indebted to their colleagues throughout the state for collecting samples and providing advice, including UCCE advisors Rick Delmas, Holly George, Neil McDougald, Gary Markegard, Wayne Jensen, Dave Pratt, Larry Forero, Chris Halpin, Sheila Barry, Rhonda Gildersleeve, Bill Frost, John Evans, Mike Connor and Gary Veserat.

\section{Further reading}

Albaugh R, Bushnell RB, Loomis EC. 1980 . Factors affecting the cattle producer's income. UC Division of Agricultural Sciences, Leaflet 2313, p 18

Corwin, RM, Nahm J. 1997. Veterinary Parasitology. University of Misssouri-Columbia, College of Veterinary Medicine. www.parasitology.org

Corwin, RM, Randle RF. 1993. Common Internal Parasites of Cattle. Department of Veterinary Microbiology, College of Veterinary Medicine, University of Missouri-Columbia. Agricultural publication G02130. http://

muextension.missouri.edu/xplor/agguides/ ansci/g02130.htm

Ensminger ME, Oldfield JE, Heinemann WW. 1990. Feeds and Nutrition, 2nd ed. Clovis, CA: Ensminger Publishing Co. p 505

Johnstone C. 1996. Parasitology 4001, Internal Parasites of Cattle. University of Pennsylvania School of Veterinary Medicine. http://cal.vet.upenn.edu/ parasit/cattle/indexcattle.html

Strickland JE. 1992. Internal parasite control in cattle. University of Georgia College of Agricultural \& Environmental Sciences in Siskiyou County, Cooperative Extension Service, Bulletin 1086. www.ces.uga.edu/pubs/b1086w.html 